\title{
PRIZE FundS
}

The Bôcher Memorial Prize.

This prize was founded in memory of Professor Maxime Bôcher. It is awarded every five years for a notable research memoir published in the Transactions of the American Mathematical Socicty during the preceding five years; the recipient must be a resident of the United States or Canada, and not more than forty years old at the time of publication of his memoir.

First (Preliminary) Award, 1923: To G. D. Birkhoff, for his memoir Dynamical systems with two degrees of freedom.

Second Award, 1924: To E. T. Bell, for his memoir Arithmetical paraphrases, and to Solomon Lefschetz, for his memoir On certain numerical invariants with applications to abelian varieties.

The Frank Nelson Prize in Algebra.

This prize was founded in honor of Professor Frank Nelson Cole, on the occasion of his retirement as Secretary of the American Mathematical Society and editor of the Bulletin, after twenty-five years of service. It is to be awarded at five year intervals for a memoir on an announced subject in algebra or the theory of numbers. The first award will be made at the end of 1927, for a contribution to the theory of linear algebras by a resident of the United States or Canada. For details, see the Bulletin of the American Mathematical Society, vol.31, p. 289.

The Eliakim Hastings Moore Fund.

This fund was founded in 1922 in honor of Professor Eliakim Hastings Moore, on the occasion of the twenty-fifth anniversary meeting of the Chicago Section of the American Mathematical Society. The interest on the fund is to be used at the discretion of the Council of the Society, for the publication of important mathematical books or memoirs or the award of prizes. 